\title{
ДИСКУССИИ
}

DOI: https://doi.org/10.15688/jvolsu2.2019.3.21

UDC 81'42:81'373.612.2

Submitted: 21.01 .2019

LBC 81.055.1

Accepted: 14.05 .2019

\section{ON LINGUISTIC AND COGNITIVE MECHANISMS OF AUTHOR'S IDENTITY REPRESENTATION IN POETIC DISCOURSE}

\author{
Irina V. Yanovskaya \\ Volgograd State Agrarian University, Volgograd, Russia \\ Olga V. Chizhikova \\ Volgograd State Agrarian University, Volgograd, Russia \\ Natalya V. Zolotykh \\ Volgograd State Agrarian University, Volgograd, Russia
}

\begin{abstract}
The purpose of the article is to justify the linguistic-and-cognitive basis of an author's identity in poetic discourse. The analysis of linguistic-and-cognitive mechanisms of artistic idiosyncrasy individuality representation is carried out on the basis of Arseny Tarkovsky's works. The hermeneutic analysis of poetics in the works by Tarkovsky allowed confirming the assumption about a Gestalt-type cognitive structure that might generate meanings erasing in image-bearing systems and depict them as the system of interpenetrating motifs. The specificity of the above named structure is in its ad hock production, which does not allow to represent it as a pattern of a syntactic type that consists of some elements. This structure has the status of a fundamental (world-forming) cognitive model, which seems immanent to a prior structure of the poet's subjectivity and acquires the highest value rank in its axiological universe. Its status of immanent mediation between powerful faceless meanings circling in the sphere of the unconscious, and the manifest (created) aspect of the artistic world, that is, its sophianic, substantive (text-forming) nature, is confirmed in the article. The semiotic and cognitive specificity of Arseny Tarkovsky's idiosyncrasy is predetermined by the fact that the metaphysical source of his texts is introspection, immanent to insight, in which the "intelligent face" of the world is revealed, that determines the gnostic character of the conceptually defining motives of his poetics.
\end{abstract}

Key words: metaphor, author's identity, poetic discourse, linguistic-and-cognitive mechanisms, idiosyncrasy.

Citation. Yanovskaya I.V., Chizhikova O.V., Zolotykh N.V. On Linguistic and Cognitive Mechanisms of Author's Identity Representation in Poetic Discourse. Vestnik Volgogradskogo gosudarstvennogo universiteta. Seriya 2. Yazykoznanie [Science Journal of Volgograd State University. Linguistics], 2019, vol. 18, no. 3, pp. 251-261. (in Russian). DOI: https://doi.org/10.15688/jvolsu2.2019.3.21

ЛИНГВОКОГНИТИВНЫЕ МЕХАНИЗМЫ ИНДИВИДУАЛЬНО-АВТОРСКОГО НАЧАЛА В ПОЭТИЧЕСКОМ ДИСКУРСЕ

\author{
Ирина Владимировна Яновская
}

Волгоградский государственный аграрный университет, г. Волгоград, Россия 


\title{
Ольга Васильевна Чижикова
}

Волгоградский государственный аграрный университет, г. Волгоград, Россия

\section{Наталья Владимировна Золотых}

Волгоградский государственный аграрный университет, г. Волгоград, Россия

\begin{abstract}
Аннотация. Цель статьи - обосновать лингвокогнитивную сущность индивидуально-авторского начала в поэтическом дискурсе. Исследование лингвокогнитивных механизмов субъективности художественного идиостиля выполнено на материале произведений Арсения Тарковского. В результате анализа поэтики его стихотворений с применением элементов герменевтики подтверждено предположение о существовании когнитивной структуры гештальтного типа, генерирующей смыслы, которые зарождаются в образных системах и реализуются в системе взаимопроникающих мотивов. Специфика названной структуры, имеющей статус становящейся формы, не позволяет сформулировать ее в виде структуры синтаксического типа, состоящей из существующих элементов. Данная структура представляет собой фундаментальную (мирообразующую) когнитивную модель, которая имманентна априорной структуре субъективности поэта и занимает высший ценностный ранг в его аксиологическом универсуме. Подтвержден ее статус имманентного опосредования между смыслами, относящимися к сфере бессознательного, и явленным (тварным) аспектом художественного мира, то есть ее софийная, текстообразующая природа. Семиотическая и когнитивная специфика идиостиля Арсения Тарковского предопределяется тем, что метафизический источник его текстов составляет интроспекция, свойственная умопостижению, в котором открывается умный лик мира. Это обусловливает гностический характер концептуально определяющих мотивов его поэтики.

Ключевые слова: метафора, индивидуально-авторское начало, поэтический дискурс, лингвокогнитивные механизмы, идиостиль.

Цитирование. Яновская И. В., Чижикова О. В., Золотых Н. В. Лингвокогнитивные механизмы индивидуально-авторского начала в поэтическом дискурсе // Вестник Волгоградского государственного университета. Серия 2, Языкознание. -2019. - Т. 18, № 3. - C. 251-261. - DOI: https://doi.org/10.15688/jvolsu2.2019.3.21
\end{abstract}

\section{Введение}

Поэзия Новейшего времени, характеризующаяся обостренной философичностью, а следовательно реализующая вертикальную тенденцию глубины в смысловой организации текста, ставит перед аналитиком проблему метафизически обусловленной избирательности художественного видения, порождающего экзистенциально невозможные в других поэтиках образы. Таковы концептуально определяющие образы и мотивы в поэзии Арсения Тарковского: Я по каменной книге учу вневременный язык, Меж двумя жерновами плыву, как зерно в камневерти, И уже я по горло в двухмерную плоскость проник, Мне хребет размололо на мельнице жизни и смерти (Тарковский, с. 337); И когда запевала свой гимн стрекоза, меж зеленых ладов проходя, как комета, Я-то знал, что любая росинка - слеза (Тарковский, с. 188); Ни тьмы, ни смерти нет на этом свете, Мы все уже на берегу морском, и я из тех, кто выбирает сети, Когда идет бессмертье косяком (Тарковский, с. 331). Образ стре- козы-кометы, проходящей меж зеленых ладов, и сама авторская интенция - Я ловил соответствия ивета и звука (Тарковский, с. 188), образы бессмертия-косяка и поэта ловца бессмертия, жизни и смерти как жерновов, размалывающих хребет человека, отличаются экстремальной субъективностью, невозможной в поэтике классического канона. Сугубая индивидуальность образов Тарковского не противоречит повышенной интертекстуальности его дискурсов.

Интуитивно ощущаемое единство символики произведений Арсения Тарковского ставит исследователя перед проблемой поиска лингвокогнитивной сущности индивидуально-авторского начала в поэтическом тексте.

В нашем исследовании выдвигается гипотеза о существовании глубинной генерирующей структуры гештальтного типа (трансцендентальной идеи), представляющей собой первоконцепцию мира, явленного в сознании того или иного значительного поэта (писателя) и отчасти им созданного. Данная структура скреплена глубокой идентичностью с индивидуальностью художника, поэтому ее мож- 
но, используя философему О. Шпенглера, обозначить как априорную структуру субъективности художника. Она выполняет зиждительную функцию, поэтому художественный текст, с точки зрения его онтологического статуса, можно назвать реализацией (инобытием) априорной структуры субъективности художника. Исследование поэзии Арсения Тарковского позволило выдвинуть предположение о том, что космогоническая доминанта идиостиля поэта, предопределяющая лингвокогнитивную специфику его поэтического дискурса, - закономерно сопряженное с модерном гностическое начало, проявляющееся не только в системе взаимопроникающих образов и мотивов, но и в смысловой организации слова.

Цель статьи - обосновать лингвокогнитивную природу априорной структуры субъективности, определить ее роль в создании семиотической специфики идиостиля Тарковского. Для этого в работе использовался метод целостного анализа стихотворного произведения, предполагающий применение элементов герменевтики.

\section{Интерпретация нереферентных смыслов в современной лингвистической парадигме}

Асемантическая и нереферентная природа сверхзначимых смыслов, скрытых в оболочке образов, не подлежит сомнению. Очевиден и наметившийся в современной когнитивной лингвистике всплеск интереса к изучению механизмов словесной репрезентации ноуменального, во многом основывающегося на интроспекции аппарата теоретического описания, непосредственным образом отражающего анализируемый феномен, а потому внутренне изоморфного ему. В данной связи следует отметить характерные для ряда современных лингвистических исследований концепты непрямой, косвенной референции, недескриптивных смыслов, небуквального значения, выдающие довлеющий над сознанием ученых феномен, - классическое языковое значение. Именно оно предопределяет точку концептуального отсчета, необходимую, но зачастую детерминирующую и едва ли не навязывающую свои способы категоризации лингвистической реальности. Так, В.Ю. Кузнецов пишет о сложившейся в современном языкознании парадоксальной ситуации, когда исследователь (как только речь заходит об означивании) попадает под неодолимый пресс дескриптивности и, таким образом, «восприятие и понимание языка оказывается сконцентрированным вокруг его прямореференциальных возможностей, при том что практически все косвенные и неявные остаются в тени» [Кузнецов, 2001, с. 218]. Это высказывание свидетельствует о модернистской переоценке феномена языкового значения в сознании аналитиков и наметившейся эволюции стиля мышления по направлению к интерпретации недескриптивных смыслов, что может привести к существенной трансформации когнитивной парадигмы и усилению ее психолингвистической направленности. Происходит ценностный сдвиг в отношении объекта исследования - им становится метафора, классический пример знака с непрямой референцией [Кузнецов, 2001, с. 219]. Парадоксальный характер данного тропа заключается в отсутствии полной произвольности: «В любом случае необходима та или иная привязка к устойчивым ассоциативным полям и спектрам интерпретативных ожиданий, иначе текст рискует достичь сингулярно замкнутого, экзотерически не воспринимаемого состояния» [Кузнецов, 2001, с. 219].

Таким образом, элемент транскаузальности, присутствующий в любой, в особенности высокохудожественной метафоре, не только не исключает, но и предполагает опору на устойчивые спектры интерпретативных ожиданий, в основе которых лежит архетипический (метафизический) прецедент, сопряженный с опытом критически осмысленной действительности. Логически структурированное и иррационально-образное в семантическом пространстве метафорического знака пребывают в семиотически напряженной структуре смешения несмесимого и разделения нераздельного (характеристика отношений ипостасей Троицы в «Слове о законе и благодати» митрополита Илариона). Именно это живое иррациональное единство предопределяет психолингвистическую и семиотическую двойственность метафоры.

Амбивалентная сущность метафоры, обращенной к таинственным объемностям, 
открывающей перед изумленным интерпретатором трансдефинитный «сверхъестественноисторический аспект становления» (по формуле О. Шпенглера [Шпенглер, 1993, с. 219]), и одновременно вожделеющей к логосу, меняет видение языка (языкочувствование) - от классического трехмерного (евклидовского) пространства к многомерному симультанному пространству множеств Минковского.

Самосознание постмодерна неустойчиво, в нем всегда коренится поиск подлинности, высших смыслов, бытийственной полноты и субстанциального единства, присущих классическому канону. Названные качества предопределяют природу слова русской классической литературы, и прежде всего святость этого слова, обладающего целостностью и потенцией благого возрастания в духе и продолжающего христианскую традицию перформативного Слова-Дела, восходящего к прецеденту Божественного Слова-демиурга. Согласно В. Топорову, «русская культура в ее вершинных проявлениях исходила из основополагающего единства Слова и “разыгрываемых" им высших смыслов, творимых художником, и из понимания Слова как духовного делания (Слово как Дело - реально, как у великих писателей, или интенционально, в виде идеальной цели, у многих других)» [Топоров, 1995, с. 220].

В контексте изучения стилистики постмодерна интерес представляют исследования Д.И. Руденко. В попытках «нетривиально и доказательно центрировать хаотично-игровую ситуацию постмодерна - прежде всего путем ответа на вопрос: что наступает после постмодерна?», ученый обращается к лингвофилософской концепции нового реализма Ю.С. Степанова [Руденко, 2001, с. 235]. В ней слову как «плотной сущности», и в особенности словуконцепту, приписывается специфическое, срединное бытие, придающее ему онтологический статус духовной реальности, а следовательно, потенциального (свернутого) текста [Руденко, 2001, с. 235]. В этой связи приведем мнение Ю.С. Степанова о том, что «русская культура реально существует в той мере, в какой существуют значения русских (и древнерусских) слов, означающих культурные концепты» [Степанов, 1997, с. 9].

Важной для концепции Д.И. Руденко является мысль Ю.С. Степанова о требовании «практической морали» Лейбница (по Лейбницу, «человек должен стремиться, в меру своих сил, познавать “достаточные основания”, то есть в ограниченном виде идти тем же путем, каким действовал Бог при создании тварного мира, осуществлять индивидуальное движение к лучшему» [Степанов, 1998, с. 753]), а также его идея о природе исследовательских интенций.

Д.И. Руденко ссылается на обобщающую книгу Ю.С. Степанова «Язык и Метод. К современной философии языка» [Степанов, 1998], в которой выдающийся лингвист и философ языка, подводя итоги исследования, отмечает, что «если устремление к Современной философии языка способствует достижению хотя бы этой, лейбницевской цели, то задача настоящей книги уже выполнена» [Степанов, 1998, с. 753].

Заметим, что требование «практической морали» базируется на одном из видов аналитических суждений (онтологических суждений, согласно Лейбницу, не бывает) суждениях о факте, анализ которых уходит в бесконечность, а завершение под силу только всезнающему существу - Богу. В этой связи можно предположить, что фактические суждения Лейбница соотносятся с индивидуально-авторской метафорой, которая является асимптотой, направленной к бесконечно удаленной точке реальности, а стремление к познанию достаточных оснований есть не что иное, как зароненное в каждом человеке тяготение к предустановленной (априорной) гармонии и целостности.

Концептуально значимым для нашего исследования представляется мнение Д.И. Руденко о том, что «стремление... к познанию “достаточных оснований” характеризует большинство социокультурных ситуаций “усталости от эклектики” - и одновременно центрирует, придает целостность эклектичным гносеологическим построениям» [Руденко, 2001, с. 235]. Следует согласиться с выводом ученого о стремлении к «познанию достаточных оснований», за которым стоит поиск уставшей от эклектики, рушащейся души современного человека - вплоть до тяготения к гнозису как окончательному возврату, когда в гностической рефлексии душа осознает не только свое экзистенциальное одиночество, но и пос- 
леднее совершенство. Именно в гнозисе происходит софийное восстановление целостности, собирание и сосредоточение души, «в рассеянии сущей», но не до конца уловленной миром (современный исследователь гностической философии Г. Ионас пишет о том, что «гнозис стучится в дверь человеческого бытия» (цит. по: [Степанов, 2004, с. 483])), как возможность противостояния силам отчуждения, обрушивающимся на современного человека.

Образ мира-ловца возник в гностическом и раннехристианском сознании Византийской империи, но вышел за концептуальные пределы Античности и приобрел значение инварианта, становясь нравственным императивом отдельной личности или предопределяя умонастроение целой эпохи. В этой связи важными представляются слова Константина Философа, который в юности не был чужд гностическим соблазнам: «Благословен Бог наш, иже не вдасть нас в ловитву зубомъ невидимых врагъ наших, но сеть их сокруши ся и избави нас от истления ихъ» (см.: [Топоров, 1995 , c. 182]).

Необходимо отметить внутреннюю противоречивость текстов постмодерна, а также осознаваемую, отчасти культивируемую авторами эфемерность и едва ли не иллюзорность их гармонии, обнаруживающей себя в оксюморонном характере глоссария. «Эклектику следовало бы определить как нечто среднее и посредничающее между духом и вожделением»; «гармония постмодерна - это та энергия, которую дает если не хаос, когда его не боятся, то эклектика» - высказывания Р. Музиля, создающие эффект экзистенциально невоспроизводимой, но несомненной истины, лишенной интуитивной застрахованности, предпосылки априорного синтеза (цит. по: [Руденко, 2001, с. 235]).

Исследования по семиотике и лингвистике текста указывают на фундаментальные особенности художественного дискурса, важнейшими из которых, по мнению В.А. Лукина, являются следующие:

- «гиперсемантизация» языкового кода (У. Вайнрайх);

- непредсказуемость элементов художественного дискурса: «Коды различных текстов сходны в том, что их важнейшие элементы должны быть непредсказуемы» (М. Риффатер);
- наличие в художественном тексте двух семиотических систем, обусловливающее принципиальную гетерогенность художественного текста: «Всякий художественный текст закодирован дважды, а следовательно, принципиально гетерогенен» (Ю. Лотман);

- бытийственный характер художественного текста, отсылающий к прустовскому мотиву реальности искусства: «...тот рассказ хорош, который... не умертвил жизни, а как бы “пересадил" ее, не повредив, в наше читательское сознание» (В. Шукшин) [Лукин, 2001, с. 586].

Перечисленные признаки относятся к общей семиотике художественного языка и не являются релевантными с точки зрения семиотической специфики художественных идиостилей, предполагающих третью семиотическую систему, в основе которой лежат лингвокогнитивные механизмы реализации авторской субъективности.

\section{Семиотическая специфика идиостиля Арсения Тарковского}

Сканирование семиотического пространства художественных текстов предполагает вовлечение в сферу исследовательских интенций мотивов и сопряженных с ними концептов и образов - как реализующих индивидуальное художественное мировидение, которое осуществляется, как правило, в пределах культурной (литературной) парадигмы, так и воплощающих национально-культурное мирочувствование (прежде всего в произведениях классического канона).

В русской литературоведческой традиции мотив интерпретируется как устойчивый формально-содержательный компонент литературного текста, выделяемый и в пределах одного (или нескольких) произведения писателя, и в контексте всего его творчества и тесно связанный с духовным миром писателя. Образы и мотивы можно рассматривать как микрокосм сознания писателя и (когда речь идет о произведениях классического канона) в большей степени локус, в котором со всей полнотой реализовался стиль мышления, присущий той или иной культурной (литературной) парадигме. Что касается мотивов и образных систем произведений авторов, отступающих от классического канона, то в связи с их экст- 
ремальной субъективностью возникает кантовская проблема «как возможно», погружающая аналитика в почти космогоническую ситуацию «приведения из небытия к бытию», становления данного художественного мира, а следовательно выдвигающая на первый план проблему авторского начала в тексте. Если речь идет о поэтическом дискурсе, такой текст приобретает статус не просто модели «чужого фантазирующего сознания», но исповеди души автора. При этом подчеркнем, что различие классического канона и послеканонических направлений в литературе весьма глубоко, в них представлены разные ценности, предопределяющие подчас противоположную направленность творческой воли.

Проблема выявления лингвокогнитивных механизмов авторской субъективности возникает и в отношении поэтического дискурса Арсения Тарковского. Герменевтическое восприятие текстов поэта ставит перед учеными проблему его индивидуальности. Это вовлекает в сферу исследовательских интенций вопросы онтологического статуса, лингвокогнитивной сущности и функций структур, peaлизующих авторское мирочувствование.

Творческое сознание Тарковского имеет духовидческий характер, о чем свидетельствует рефлексивное высказывание поэта, определяющее доминирующую модальность в его поэтике мировосприятия: И странно: от всего живого Я принял только свет и звук, Еще грядущее ни слова Не заронило в этот круг... (Тарковский, с. 330). Поэт умел видеть невидимое и слышиать неслышимое (слова Игоря Золотусского о Владимире Набокове) и, подобно Набокову, модернистски разрушал классический канон, «засвечивая» смыслы, кружащие в сфере бессознательного, - смыслы, которые лишают слово софийной целостности и, в сущности, ставят его по ту сторону добра и зла. Болезненная утонченность некоторых смыслов Тарковского свидетельствует о своеобразном растлении слова (значение общеславянского слова тло - «испод, основа, то, что находится под спудом» (Даль, с. 408) и не должно выводиться наружу, то есть изображаться или подвергаться концептуализации).

В поэзии Тарковского этот процесс едва намечен, однако смысловая структура его текстов наводит на мысль о своевольной Со- фии гностиков, «рождающей чудовищ». Гностическая аберрация поэтического видения Тарковского вызвана тем, что объектом его изображения является «умный лик» вещей, порождающий в его поэзии «образы образов», то есть вторгающийся в ускользающую от рефлексии область сверхзначимых и безликих проблем, знакомую гностикам.

К модернистским смыслам, разрушающим диатоническую основу семантики классического высказывания и раскалывающим читательское восприятие на «ультрахроматические механизмы реагирования» (К.А. Свасьян о стилистике книги О. Шпенглера «Закат Европы»), относятся, в частности, образы-смыслы стихотворения А. Тарковского «Я учился траве...». Они всплывают из глубины и укоренены в особого рода внутренней чувственности, отделенной от оптически связанного восприятия. Их визионерный и гностический характер очевиден. Это вынужденные и насильственные образы, добываемые в мучительной интроспекции. Напряженность дискурса Тарковского сродни драматизму гностических текстов; жизнеборческая отказчивость его текстов свидетельствует о космическом сиротстве его души, обретающей экзистенциальную полноту перед лицом смерти и воскресения в духе. Мотив сиротства присутствует в поэтике Тарковского и закономерно сопряжен с гностическим мотивом аннигиляции пространства и числа: Не надо мне числа; я был, и есмь, и буду. Жизнь - чудо из чудес, и на колени чуду один, как сирота, я сам себя кладу...(Тарковский, с. 376).

К гностическим относятся и мотивы перформативного слова, «выколдовывающего» действительность и равного ей: $B$ слове «правда» мне сльшиалась правда сама (Тарковский, с. 188), и мотивы неудовлетворенности: Я тень из тех теней, которые, однажды испив земной воды, не утолили жажды (Тарковский, с. 377), неподлинности бытия: Я тот, кто жил во времена мои, но не был мной (Тарковский, с. 295), памяти и Слова как условий бессмертия, присутствующие в Евангелии от Иоанна: Что, если память вне земных условий Бессильна день восстановить в ночи? Что, если тень, покинув землю, в слове не пьет бессмертья? (Тарковский, с. 564). 
Гностический мотив преображения предопределяет поэтику переломного цикла «После войны», в котором используется дендрологический код - образ обрушивающегося корнями вверх, разбрызгивающего землю над собой дерева, плывущего по быстрине, перебирающей ветви; дерева, олицетворяющего тварную ипостась лирического героя, отслоившуюся от внезапно обретенной подлинной сущности и названную Лазарем. Обрушившееся древо - образ Лазаря, - является в евангельском тексте амбивалентным символом смерти-воскресения, но в тексте Тарковского - символом тлетворности жизни, которая сильнее тлетворности смерти, тлетворности, отсылающей к прецедентному тексту Константина Философа о Слове, решающем духовную задачу отлучения человека от «тления плоти гноящей». Именно с этой стороной личности прощается лирический герой, осознавший свою внутреннюю слабость: Вослед себе я с высоты смотрю и за сердие хватаюсь. Кто мне дал трепещущие ветви, мошный ствол и слабые, беспомощные корни? (Тарковский, с. 280). Далее поэт высказывает парадоксальную мысль, в которой в полной мере воплотился жизнеборческий характер его мирочувствования и творческой воли: Тлетворна смерть, но жизнь еще тлетворней (Тарковский, с. 280).

В поэтике Тарковского представлен феномен разложения гармонии средствами красочности, описанный в исследовании Эрнста Курта «Романтическая гармония и ее кризис в "Тристане" Рихарда Вагнера» (см.: [Свасьян, 1993]). Данный феномен реализуется в смысловой организации как всего текста, так и поэтического слова; предопределяет «развоплощающий» характер словопреображения в поэтическом дискурсе Тарковского; обусловливает центробежные тенденции в семантическом пространстве слова поэта; втягивает читателя в особое пространство, где противопоставление субъекта и объекта преодолено, снято. Возникающая красочность оттесняет денотативную и сигнификативную (понятийную) основу семантики поэтического слова Тарковского: «Это расползающееся в туман, экстатическое, становящееся все более призрачным и магическим слово, эти самоуничтожающиеся смыслы, являющиеся выражением византийской души Тарковского, трассируют поверх читательского восприятия, ориентированного на золотой канон классической русской литературы» [Чижикова, Яновская, 2017, с. 73]. Экстремальная субъективность образных систем поэта, взвинченная духовная экспрессия его искусства, лишенного всякого намека на самодовлеющую телесность и стремящегося к самоуничтожению, ставит исследователя перед проблемой когнитивной сущности искусства Тарковского, а следовательно, возникает проблема метода ее изучения.

\section{Лингвокогнитивный аспект}

\section{индивидуально-авторского начала в поэтическом дискурсе}

В отличие от обыденного дискурса, сложность которого преимущественно экстенсивна, художественный дискурс сложен интенсивно, что обусловлено особым характером его символики, предполагающим решение специфической проблемы эстетического словопреображения в поэзии. При этом анализ художественных миров менее многомерен, по сравнению с изучением обыденного дискурса. Типичные схемы практической и коммуникативной деятельности и фреймовых моделей, содержащих информацию социокультурного характера, как правило, не находятся в фокусе внимания исследователя. Художественные миры в их априорной целостности выдвигают на первый план проблему лингвокогнитивной природы личностного начала. Они позволяют применить феноменологический метод, который является радикально антропологическим, а точнее душецентрическим, ибо отражает основной принцип искусства: онтологическую субъективность (самость) как условие целостного когнитивно-дискурсивного моделирования действительности, выступающей в подобной модели как умопостигаемая реальность. При феноменологическом подходе речь идет о существовании субъективных когнитивных структур, обращенных к личному опыту каждого и всей системе знаний о мире в целом, то есть тех структур сознания, которые помечают предопределенные авторской индивидуальностью концептуальные границы его художественного мира. По- 
добный метод не может не быть герменевтическим, по крайней мере, на начальном этапе исследования. Герменевтический метод предполагает допредикативное переживание индивидуально-авторского текста, когда исследователь позволяет тексту непосредственно воздействовать на чувства, присваивает априорную целостность впечатления и, развивая ее до трансцендентной глубины, интерпретирует его в метафизических категориях. Этот метод означает аскетическое самоограничение ученого, а именно: исходное владение только одной данностью - смысловым переживанием символа, концепта, текста в целом в его непосредственности, поэтому теория на начальном этапе становится дешифровкой эзотерического переживания, в котором пытаются отыскать трансцендентальные предпосылки когнитивной организации символического универсума данного идиолекта. В нем открывается сверхъестественно-исторический аспект становления символики и текста в целом: преодолевается частичность ставшего, наличного, экстенсивного и эксплицитного в символе (тексте), фиксируемого понятийно-дискурсивным познанием, и частичность самого символа или текста, а также совершается «выход не в экстенсивное вовне, а в интенсивную внутреннюю глубину» [Топоров, 1995, с. 79].

Подобный подход имманентен реальности (в нем объект предстает не на объектном расстоянии, а как непосредственная данность в гностическом переживании глубинноонтологического всеединства реальности) и рефлексивен, поскольку является не только познанием, но и самопознанием. В какой-то степени он соотносится с философемой гностического знания - Софией-Премудростью, которая «в качестве осуществляющейся потенции абсолютного всеединства обеспечивает максимальный уровень самопознания в мире и может быть уподоблена стреле эволюции, которая неустанно порождает и осознает самое себя» [Топоров, 1995, с. 79]. Естественно, что герменевтический способ анализа художественных идиолектов сопряжен с возможностью «гностических соблазнов и без контроля волевого, логосного и эмпирического начала, без осознания исследователем собственных целей и истоков таит определенную опасность», как пишет В. Топоров о переживании Софии-Премудрости Божией [Топоров, 1995 , с. 80]. Герменевтический метод позволяет прочувствовать трансцендентальную идею, обладающую статусом демиурга и первопричины по отношению к препостулируемому ею художественному миру, или установить субъективную психическую структуру (когнитивную конструкцию) детерминирующего характера, которая сообщает художественному миру внутреннее единство.

Глубинные когнитивные структуры выводятся из переживания априорной целостности. Они являются способами репрезентации знания, существующими в мозгу индивида, и выходят за рамки когнитивного сценария Ж. Пиаже, согласно которому познание начинается с действия, а всякое действие повторяется (генерализуется) через применение к новым объектам, порождая тем самым некоторую «схему» - своего рода праксический концепт [Пиаже, 2001, с. 99].

Внутреннее единство идиолектов значительных художников (подобные идиолекты характеризуются интенсивностью символики) предопределяется детерминирующей когнитивной структурой, которую, вслед за О. Шпенглером, назовем априорной структурой субъективности (АСС) художника. Психолингвистической предпосылкой возникновения АСС является доказанный в когнитивной науке «факт наличия у индивида системы модальностей восприятия, благодаря которой осуществляется общение индивида и реальности. Качественные различия между модальностями можно... объяснить различиями в функциональной организации сенсорных анализаторов модальности, которыми располагает индивид» [Калашникова, 2006, с. 20]. АСС представляет собой метафизическую абстракцию высокого ранга, возникающую как когнитивная модель прочувствованного времени-становления, или трансцендентальная идея становящегося пространства (прочувствованный смысл времени, который выражается через пространство). АСС - это макрометафора, инициирующая концептуализацию мира художником и, следовательно, являющаяся источником, генерирующим образы-символы до тех пор, пока не будет изжита. 
Вопрос об априорном статусе АСС является дискуссионным и уводит исследование в область психологии. Ж. Пиаже утверждал, что у человека «не существует априорных или врожденных когнитивных структур: наследственным является лишь функционирование интеллекта, которое порождает структуры через организацию последовательных действий, осуществляемых над объектами» [Пиаже, 2001, с. 98]. Независимо от того, признаем ли мы данную когнитивную структуру априорной или апостериорной, на первый план выдвигается проблема генезиса данной структуры и ее семиотической специфики.

\section{Выводы}

Исследование лингвокогнитивных механизмов субъективности художественного идиостиля применительно к поэтическому дискурсу Арсения Тарковского позволило подтвердить гипотезу существования глубинной структуры гештальтного типа, генерирующей асемантические смыслы, которые возникают в образных системах и находят воплощение в интегрированной системе взаимопроникающих мотивов, избранных с безальтернативной внутренней самоочевидностью. Специфика названной структуры, имеющей статус становящейся формы, не позволяет сформулировать ее в виде системы синтаксического типа, состоящей из наличных, ставших элементов. Данная структура гештальтного типа представляет собой фундаментальную (мирообразующую) когнитивную модель, которая имманентна априорной структуре субъективности поэта и занимает высший ценностный ранг в его аксиологическом универсуме. В результате исследования подтвержден ее статус имманентного опосредования между смыслами, относящимися к сфере бессознательного, и явленным (тварным) аспектом художественного мира.

Семиотическая и когнитивная специфика идиостиля Арсения Тарковского предопределяется тем, что на первый план выступает не столько созерцание мира через призму субъективности поэта, сколько напряженная, полная страстной взволнованности интроспекция, имманентная умопостижению, в котором открывается умный лик мира, и переходящая в почти насильственное сканирование внутренне- го пространства, в мучительный внутренний допрос. Объект художественного изображения является объектом второго порядка: это не мир, а его ноуменальный аспект - умопостигаемое и сам процесс умопостижения, иными словами, первый ум гностиков, в котором ум и умопостигаемое - одно по числу. Сказанное обусловливает специфику поэтики Тарковского. Искусство поэта - жизнеборческое и умозрительное, лишенное самодовлеющей телесности. Вспышки духовной экспрессии в поэтике метафизически родственны пробелам в иконописной технике Феофана Грека. Поэзия Арсения Тарковского пронизана ослепительным холодным светом Преображения, светом Григория Паламы, в ней веет сухая душа византийских мистиков. Лирическое «я» когнитивно, в высшей степени духовно и интеллектуально, его самовыражение - это самовыражение гностика. Актуально совершающийся гнозис предопределяет единство символики Тарковского, и прежде всего систему образов и мотивов, в основе которой лежит принцип соборности.

Магическая душа поэта чувствовала мир как таинственное единство, пронизанное духовной субстанцией высшего ранга, единственно придающей ему онтологический статус. Это обусловило и ценностную обостренность дискурсов Тарковского, и экстремальную энергию развоплощения, предопределившую избирательность его художественного зрения, и лингвокогнитивную сущность его слова, в котором властвует динамика центробежных, рвущихся наружу смыслов.

\section{СПИСОК ЛИТЕРАТУРЫ}

Калашникова Л. В., 2006. Метафора как механизм когнитивно-дискурсивного моделирования действительности (на материале художественных текстов) : автореф. ... дис. д-ра филол. наук. Волгоград. $40 \mathrm{c}$.

Кузнецов В. Ю., 2001. Философия языка и непрямая референция // Язык и культура. Факты и ценности : сб. ст. / отв. ред. Е. С. Кубрякова, Т. Е. Янко. М. : Яз. слав. культуры. С. 217-224.

Лукин В. А., 2001. «Как-художественный» текст и его структура // Язык и культура. Факты и ценности : сб. ст. / отв. ред. Е. С. Кубрякова, Т. Е. Янко. М. : Яз. слав. культуры. С. 585-595. Пиаже Ж., 2001. Схемы действия и усвоение языка // Семиотика: антология / сост. Ю. С. Степа- 
нов. 2-е изд., испр. и доп. М. : Акад. проект ; Екатеринбург : Деловая кн. С. 144-150.

Руденко Д. И., 2001. «Новый русский реализм»: в берегах и вне берегов постмодернизма // Язык и культура. Факты и ценности : сб. ст. / отв. ред. Е. С. Кубрякова, Т. Е. Янко. М. : Яз. слав. культуры. С. 235-246.

Свасьян К. А., 1993. Освальд Шпенглер и его реквием по Западу // Закат Европы. Очерки морфологии мировой истории : в 2 т. / О. Шпенглер. М. : Мысль. Т. 1. С. 5-19.

Степанов Ю. С., 1997. Константы: словарь русской культуры. Опыт исследования. М. : Акад. проект. 824 c.

Степанов Ю. С., 1998. Язык и Метод. К современной философии языка. М. : Яз. рус. культуры. $784 \mathrm{c}$.

Степанов Ю. С., 2004. Константы: словарь русской культуры. 3-е изд., испр. и доп. М. : Акад. проект. 992 с.

Топоров В. Н., 1995. Святость и святые в русской духовной культуре. Первый век христианства на Руси : в 2 т. М. : Гнозис ; Яз. рус. культуры. T. $1.874 \mathrm{c}$.

Чижикова О. В., Яновская И. В., 2017. Мотив перформативного слова в поэзии Арсения Тарковского // Филологические науки. Вопросы теории и практики. № 12 (78), ч. 3. C. $72-76$.

Шпенглер О., 1993. Закат Европы. Очерки морфологии мировой истории : в 2 т. М. : Мысль. T. $1.667 \mathrm{c}$.

\section{ИСТОЧНИК}

Тарковский - Тарковский А. А.. Стихотворения. Поэмы. М. : Э, 2017. 544 с.

\section{СЛОВАРЬ}

Даль - Даль В. И. Толковый словарь живого великорусского языка : в 4 т. 5-е изд., стер. М. : Дрофа : Рус. яз. Медиа, 2008. Т. 4. 683 с.

\section{REFERENCES}

Kalashnikova L.V., 2006. Metafora kak mekhanizm kognitivno-diskursivnogo modelirovaniya deystvitelnosti (na materiale khudozhestvennykh tekstov): avtoref. ... dis. d-ra filol. nauk [Metaphor as a Mechanism for Cognitive-Discursive Modeling of Reality (On the Material of Literary Texts). Dr. philol. sci. diss.]. Volgograd. 40 p.
Kuznetsov V.Yu., 2001. Filosofiya yazyka i nepryamaya referentsiya [Philosophy of Language and Indirect Reference]. Yazyk $i$ kultura. Fakty $i$ tsennosty [Language and Culture. Facts and Values]. Moscow, Yazyki slavyanskoy kultury Publ., pp. 217-224.

Lukin V.A., 2001. «Kak-khudozhestvennyy» tekst i ego struktura [How-Fiction Text and Its Structure. Language and Culture. Facts and Values]. Moscow, Yazyki slavyanskoy kultury Publ., pp. 585-595.

Piaget J., 2001. Skhemy deystviya i usvoenie yazyka [Schemes of Action and Language Learning]. Semiotika: antropologiya [Semiotics: Anthology]. Moscow, Akademicheskiy Proekt Publ.; Yekaterinburg, Delovaya kniga Publ., pp. 144-150.

Rudenko D.I., 2001. «Novyy russkiy realizm»: v beregakh i vne beregov postmodernizma ["New Russian Realism": In the Shores and Beyond the Shores of Postmodernism]. Kubryakova E.S., Yanko T.E., eds. Yazyk i kultura. Fakty $i$ tsennosti: sb. st. [Language and Culture. Facts and Values. Collected Articles]. Moscow, Yazyki slavyanskoy kultury Publ., pp. 235-246.

Svasyan K.A., 1993. Osvald Shpengler i ego rekviem po Zapadu [Oswald Spengler and His Requiem on the West]. Shpengler O. Zakat Evropy. Ocherki morfologii mirovoy istorii: $v 2 t$. [Sunset of Europe. Essays on the Morphology of World History. In 2 vols]. Moscow, Mysl Publ., vol. 1, pp. 5-19.

Stepanov Yu.S., 1997. Konstanty: slovar russkoy kultury. Opyt issledovaniya [Constants: Dictionary of Russian Culture. Research Experience]. Moscow, Akademicheskiy proekt Publ. 824 p.

Stepanov Yu.S., 1998. Yazyk i Metod. K sovremennoy filosofii yazyka [Language and Method. Toward the Modern Philosophy of Language]. Moscow, Yazyki russkoy kultury Publ. 784 p.

Stepanov Yu.S., 2004. Konstanty: slovar russkoy kultury [Constants. Dictionary of Russian Culture]. Moscow, Akademicheskiy proekt Publ. 992 p.

Toporov V.N., 1995. Svyatost i svyatye v russkoy dukhovnoy kulture. Pervyy vek khristianstva na Rusi: v 2 t. [Holiness and Saints in Russian Spiritual Culture. In 2 vols.]. Moscow, Gnosis Publ., Yazyki russkoy kultury Publ., vol. 1. 874 p.

Chizhikova O.V., Yanovskaya I.V., 2017. Motiv performativnogo slova $\mathrm{v}$ poezii Arseniya Tarkovskogo [The Motive of Performative Word in Arseny Tarkovsky's Poetry]. Filologicheskie nauki. Voprosy teorii i praktiki [Philological Sciences. Issues of Theory and Practice], no. 12 (78), part 3, pp. 72-76.

Shpengler O., 1993. Zakat Evropy. Ocherki morfologii mirovoy istorii: $v 2 t$ [Decline Of Europe. Essays 
И.В. Яновская, О.В. Чижикова, Н.В. Золотьхх. Лингвокогнитивные механизмы индивидуально-авторского начала

on World History Morphology. In 2 vols.]. Moscow, Mysl Publ., vol. 1. 667 p.

\section{SOURCE}

Tarkovskiy A.A. Stikhotvoreniya. Poemy [Poesy. Poems]. Moscow, E Publ., 2017. 544 p.

\section{DICTIONARY}

Dal V. I. Tolkovyy slovar zhivogo velikorusskogo yazyka: $v 4 t$. [Explanatory Dictionary of the Living Great Russian Language. In 4 Vols.]. Moscow, Drofa Publ., Russkiy yazyk Media Publ., 2008, vol. 4. 683 p.

\section{Information about the Authors}

Irina V. Yanovskaya, Candidate of Sciences (Philology), Associate Professor, Department of Pedagogy and Methods of Professional Education, Volgograd State Agrarian University, Prosp. Universitetsky, 26, 400002 Volgograd, Russia, pedagogika25@mail.ru, https://orcid.org/0000-0002-9208-2271

Olga V. Chizhikova, Candidate of Sciences (Philology), Associate Professor, Department of Pedagogy and Methods of Professional Education, Volgograd State Agrarian University, Prosp. Universitetsky, 26, 400002 Volgograd, Russia, pedagogika25@mail.ru, https://orcid.org/0000-0003-4329-9439

Natalya V. Zolotykh, Candidate of Sciences (Philology), Associate Professor, Department of Pedagogy and Methods of Professional Education, Volgograd State Agrarian University, Prosp. Universitetsky, 26, 400002 Volgograd, Russia, pedagogika25@mail.ru, https://orcid.org/0000-0002-4586-510X

\section{Информация об авторах}

Ирина Владимировна Яновская, кандидат филологических наук, доцент кафедры педагогики и методики профессионального обучения, Волгоградский государственный аграрный университет, просп. Университетский, 26, 400002 г. Волгоград, Россия, pedagogika25@mail.ru, https://orcid.org/0000-0002-9208-2271

Ольга Васильевна Чижикова, кандидат филологических наук, доцент кафедры педагогики и методики профессионального обучения, Волгоградский государственный аграрный университет, просп. Университетский, 26, 400002 г. Волгоград, Россия, pedagogika25@mail.ru, https://orcid.org/0000-0003-4329-9439

Наталья Владимировна Золотых, кандидат филологических наук, доцент кафедры педагогики и методики профессионального обучения, Волгоградский государственный аграрный университет, просп. Университетский, 26, 400002 г. Волгоград, Россия, pedagogika25@mail.ru, https://orcid.org/0000-0002-4586-510X 